\title{
The application of phytoremediation method to wastewater treatment of nickel ore extraction industry based on the expert stakeholder perspective
}

\author{
Erikha Maurizka Mayzarah ${ }^{1}$, Setyo Sarwanto Moersidik ${ }^{2, *}$, and Lana Saria $^{3}$ \\ ${ }^{1}$ School of Environmental Science, Universitas Indonesia, Indonesia \\ ${ }^{2}$ Environmental Engineering Program, Faculty of Engineering, Universitas Indonesia, Indonesia. \\ ${ }^{3}$ General Directorate of Mineral and Coal, Ministry of Energy and Mineral Resources, Indonesia
}

\begin{abstract}
The use of chemical-based wastewater treatment method may cause harm to the environment. The aim of this research is to identify the flow application of wastewater treatment using phytoremediation method and summarize the perspective from stakeholders regarding the application based on long-term and short-term categories. In-depth interview was done with expert stakeholders from the sectors of government, private and academics. Subsequently, the scenario of wastewater treatment and the result of phytoremediation research that will be applied on nickel ore extraction industry were confirmed. Finally, a summary of the in-depth interview is shown on a form of a figure. The result shows that this method application needs effort and decision making from the company's part that become the short-term issue for the company. However, on long-term side, phytoremediation is able to benefit the environment, social, and economy.
\end{abstract}

\section{Introduction}

The controversy of environmental pollution is increasing on humans' life and ecosystem [1]. This reduces the development of economic status, humans' sustainability and environment [2]. Environmental pollution that vastly developed is water pollution due to wastewater disposal from [1].

PT Vale Indonesia Tbk is one of the companies that works in mining and nickel ore extraction sector. Wastewater treated on settlement pond of this company has chromium hexavalent content of approximately 0.1-6.28 ppm [3]. Chromium hexavalent has poisonous effect that may induce carcinogenic to humans [4]. This company has done wastewater treatment which include chromium hexavalent treatment using coagulation method. Where ferrous sulfate as the coagulant of this method. This treatment is effective to reduce chromium hexavalent, however using chemical-based method and having residual

\footnotetext{
* Corresponding author: ssarwanto@ui.ac.id
} 
chemical material may impact the environment negatively in the long term [5]. Moreover, this method is very expensive.

One of the methods to evaluate the environmental impact due to the wastewater treatment system is by using Life Cycle Assessment (LCA) [6]. LCA is a holistic method of analysis that quantifies the environmental impacts of a product, process, or system by tracking the material and energy flows from a raw material extraction through manufacturing and use to the end of life [7]. This research proposed process analysis from input-output that are parts of Life Cycle Inventory. Where Life Cycle Inventory is a model of a product's life cycle, connects input and output from process to functional unit, and subsequently compiles all relevant intervention, such as environmental burden emission and sources consumption [8].

The decision of using phytoremediation method to substitute coagulation method is taken because this method is environmentally friendly and economic, moreover it can treat polluted water due to heavy metal [9]. Early research showed that phytoremediation method has the efficiency rate of $89 \%$ on 20 days with batch scale [10].

The aims of this research are: (1) to identify the application of wastewater flow treatment with phytoremediation technology in PT Vale Indonesia Tbk; (2) to summarize stakeholders' perspective on the application of phytoremediation method based on short term and long term categories

\section{Method}

This research was done in PT Vale Indonesia, Tbk, Nuha Sub-district, East Luwu District, South Sulawesi, Indonesia. This research proposed other scenario for wastewater treatment to substitute the current method used by PT Vale Indonesia Tbk. The scenario was confirmed to stakeholders of wastewater treatment regarding this nickel industry. Subsequently, that confirmation was done through in-depth interview with expert stakeholders from the sectors of government, private and academics with 6 total of 6 people. One interview session with each stakeholder takes 2 hours. Then, the summary of the In-depth interview result is shown on a flowchart for clarity.

\section{Results and discussion}

Wastewater treatment that has been implemented by PT Vale Indonesia Tbk can be seen on Figure 1. Coagulant used by PT Vale Indonesia Tbk in Lorraine Pond on 2017 was 25.403 $\mathrm{kg}$ [3]. This is influenced by some factors, which are: (1) temperature of water, (2) degree of acidity ( $\mathrm{pH}$ ), (3) coagulant type, (4) dissolved ion content, (5) degree of turbidity, (6) coagulant dose, and (7) stirring speed. Moreover, the quantity of the sludge increases when the coagulant technology is used. Thus, company need extra budget to excavate sludge that will then be dumped on landfilling.

Based on the explanation below and research by Mayzarah et al. [10], thus two scenario were proposed for wastewater treatment that can be applied by PT Vale Indonesia Tbk (Figure 2). If the chromium hexavalent content is slightly above the threshold criteria (0.011-2 ppm) then the applied wastewater treatment is the substitution of coagulation method to phytoremediation method. This substitution is done because phytoremediation method is best at reducing chromium hexavalent with the low content of chromium hexavalent. 


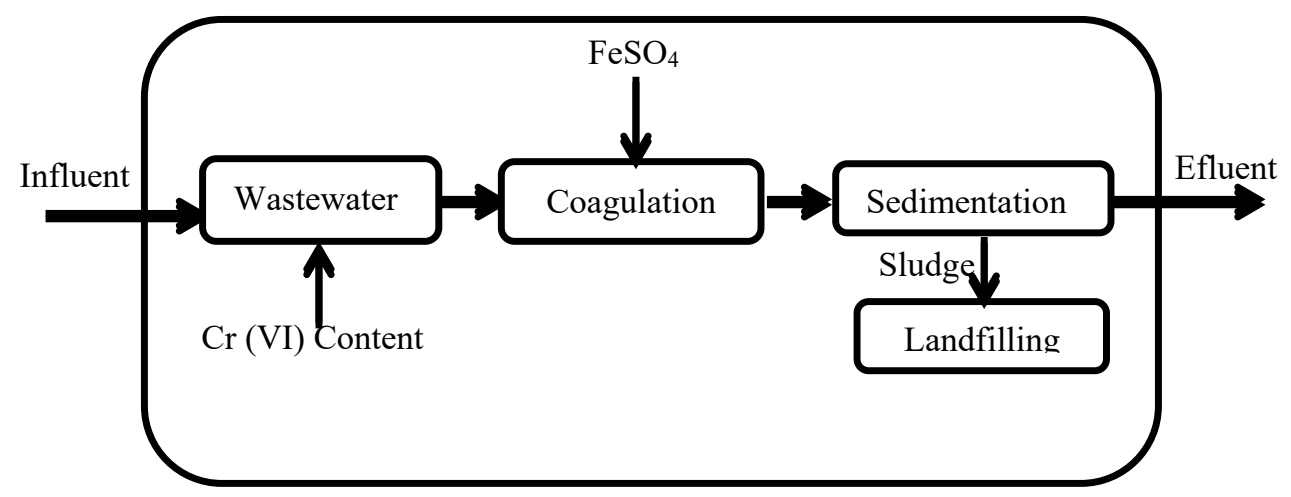

Fig. 1. Flowchart of wastewater treatment.

When the content of chromium hexavalent is really high then the scenario of adding phytoremediation method is applied prior to entering the treatment stage using coagulation method. This is done to decrease the usage of ferrous sulfate thus the impact and budget are also decreased. This research supports the research by [10] which showed that the higher chromium hexavalent concentration, the efficiency rate of $\mathrm{Cr}(\mathrm{VI})$ reduction will be decreased thus other wastewater treatment method is needed to be added.

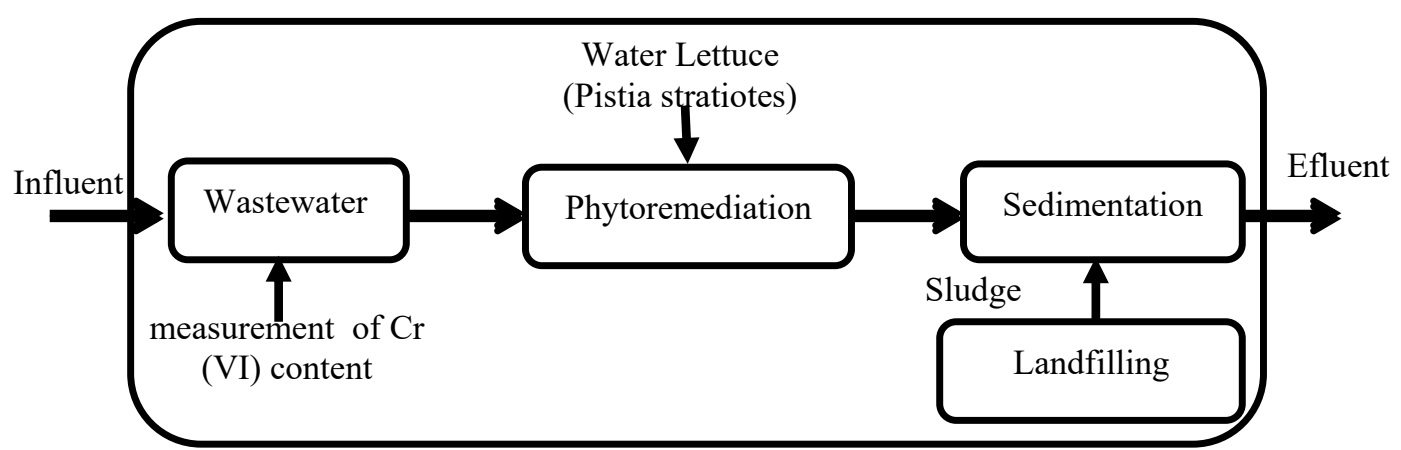

(a)

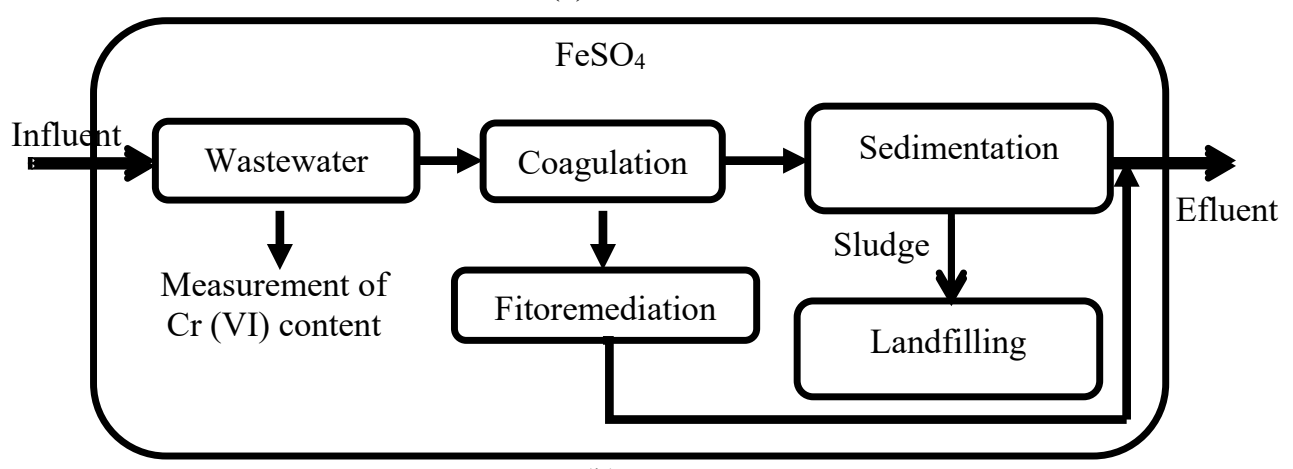

(b)

Fig. 2. The scenario of wastewater treatment: (a) substitution of coagulation method to phytoremediation method; (b) adding phytoremediation method 
Based on the wastewater treatment scenario that has been proposed, it was then confirmed to the stakeholders. The summary of in-depth interview with the stakeholders indicate is shown in Figure 3. The contribution of phytoremediation method application on Figure 3 shows three sustainable development aspects, such as: (1) environmental aspect, (2) economy aspect, (3) social aspect. On environmental aspect, phytoremediation method application helps to minimize the impact of using chemical materials for wastewater treatment. Moreover, it also helps to maintain ecosystem's health that located on the surrounding of wastewater treatment pond.

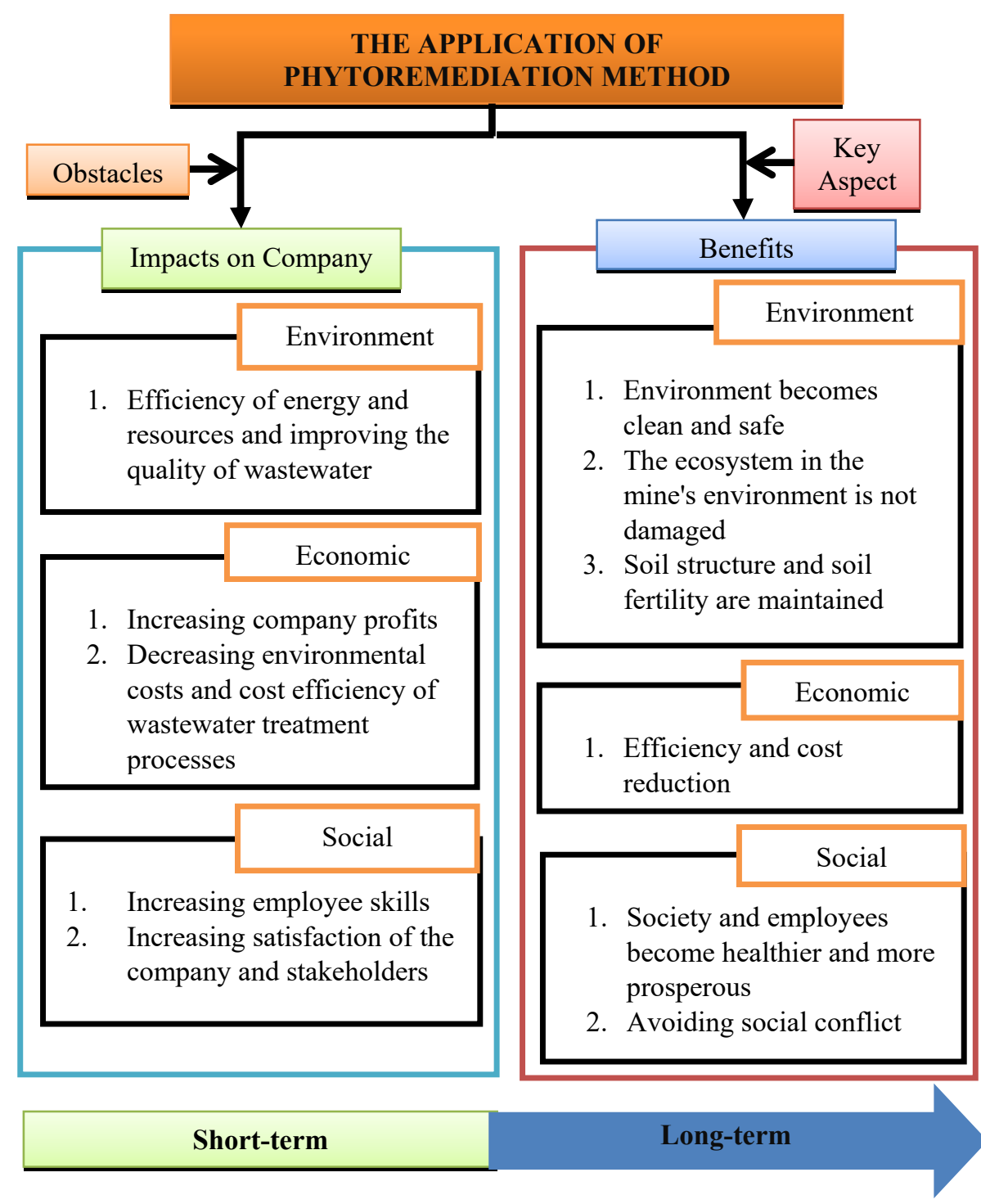

Fig. 3. Summary of in-depth interview with expert stakeholders regarding phytoremediation method.

On the social aspect, the coagulation method application decreases the monitoring activity and works on wastewater treatment, decreases pollutant to the environment, thus 
the implicit benefit gained by the employees and community is health and environmental security. Economy aspect can benefit the company through: (1) decrease of cost from the resource, energy and process efficiency, (2) no loss from social conflict, employees' health issue and environmental damage

Table 1 shows that the difference in efficiency rate is on batch and continuous scale. Where the efficiency rate of batch scale is higher compared to continuous scale. According to the stakeholders, this is due to the difference in chromium hexavalent concentration, speed of flow and rainfall. Rainfall influences the speed of flow. When the speed of flow changes, then HRT on continuous scale also changes. Moreover, mining activities such as excavation of limonite and saprolite layers also become obstacles. Where the increase in excavation influences the increase of chromium hexavalent on groundwater and increases the flow that goes to the settlement pond inlet. However, using young and healthy plants can increase the absorption of chromium hexavalent.

Table 1. The maximum, minimum, average and standard deviation of Chromium Hexavalent Reduction Test with Phytoremediation Technology [10]

\begin{tabular}{ccccc}
\hline Observation & Min (\%) & $\operatorname{Max}(\%)$ & Average(\%) & Dev. Std \\
\hline $\mathbf{1}$ & 11 & 27 & 19 & 6 \\
$\mathbf{3 a}$ & 79 & 99 & 89 & 7 \\
$\mathbf{3 b}$ & 5 & 59 & 30 & 8 \\
$\mathbf{3 c}$ & 2 & 61 & 28 & 5 \\
\hline $\begin{array}{l}\text { Notes: } \\
\text { 1 and } 2=\text { Batch Scale } \\
3 a, 3 b, \text { and 3c }=\text { Continue Scale }\end{array}$ & 5 & 59 & 27 & 6 \\
\hline
\end{tabular}

This is in accordance with Kumar et al. [11] which stated that phytoremediation method is more environmentally friendly because it uses plants, it does not give any harm because it does not have side effects. The treatment is in situ, does not need contaminated material to be transported to other places thus the cost is cheaper. Although the experiment result in continuous scale [10] still does not indicate high efficiency rate, it was believed that if phytoremediation method is done with good care and high intention, the desired efficiency rate can be achieved.

\section{Conclusion}

Phytoremediation method application has to consider chromium hexavalent content on wastewater. This consideration is to choose the wastewater treatment scenario of either changing coagulation method or only adding phytoremediation method to wastewater from nickel ore extraction industry. Moreover, the application of this method needs effort and decision making from the company thus become short-term obstacle to the company. However, on the long-term, phytoremediation method can provide benefit in the aspect of environment, social, and economy. Unfortunately, currently there are still so many industries that put environmental aspect aside and still do not fully aware of the importance of maintaining harmonization of the economy-environmental-social interaction to achieve 
sustainability, thus the usage of chemical materials for wastewater treatment is still really popular.

\section{Acknowledgements}

This research was funded by HIBAH PITTA 2018 from DRPM University of Indonesia No.2583/UN2.R3.1/HKP.05.00/2018 and supported by PT Vale Indonesia Tbk.

\section{References}

1. C. F. Carolin, P. S. Kumar, A. Saravanan, G. J. Joshiba, Mu. Naushad. J. Of. Env. Chem. Eng. (2017)

2. M. Elgallal, L. Fletcher, B. Evans. Agric. Water Manag. 177, 419-431. (2016).

3. Vale Indonesia Tbk. Geotechnical and hydrology Section Report. (2017)

4. A.N. Modenes, A.P. de Oliveira, F.R. Espinoza-Quinones, D.E.G. Trigueros, A.D. Kroumov, R. Bergamasco. Chem. 172, 373-383. (2017)

5. P. Saha, O.Shinde, S. Sarkar, Int. J.of Phyt. 19, 1, 87-96.(2017).

6. M. Sena, A. Hicks. Resourc., Conserv, and Rec. 139, 194-204. (2018).

7. ISO. The New International Standards for Life Cycle Assessment: ISO 14040 and ISO 14044. (2006)

8. J. Nakatani, Sustainability. 6, 6158-6169. (2014)

9. D. H. K. Reddy, Wat. Pol. C. Tech. 3-22. (2017).

10. E.M. Mayzarah, S.S. Moersidik, L. Saria. The $1^{\text {st }}$ Sriwijaya Internasional Conference on Environmental Issues. (2018).

11. V. Kumar, J. Singh, A.K. Chopra. Int. J. of Phyt. 20, 5, 507-521. (2018). 